\title{
The Safety of Induced Sputum Collection IN INFANTS UNDER THE AGE OF 18 MONTHS.
}

\begin{abstract}
The technique of sputum induction improves the yield of microbiological investigations for organisms such as Mycobacterium tuberculosis and Pneumocystis carinii. The aim of the study was to determine the safety of this method in children under the age of 18 months. Heart rate and oxygen saturation were monitored during the procedure and compared with measurements obtained during the conventional method of sputum collection in the same patients. Patients were also observed for other possible side effects. Forty samples of sputa were obtained from 20 patients. No clinical differences in heart rate and oxygen saturation were found between the two methods.

VAN WYK H, BSc Physiotherapy '; JACQUEMARD R ${ }^{2}$; JOUBERT $\mathrm{G}^{3}$

\author{
1 Department of Physiotherapy \\ Universitas Hospital, Bloemfontein, \\ 2 Department of Paediatrics and Child Health, \\ ${ }_{3}$ University of the Orange Free State, Bloemfontein \\ ${ }^{3}$ Department of Biostatistics, \\ University of the Orange Free State, Bloemfontein
} Overall, oxygen saturation measurements below $80 \%$ were recorded in three patients. Increased coughing and mild epistaxis did occur more frequently during the sputum induction method. It was concluded that sputum induction is safe in small children, but a larger sample size needs to be studied.
\end{abstract}

\section{KEY WORDS: SPUTUM INDUCTION, SAFETY, SIDE EFFECTS, OXYGEN SATURATION, CHILDREN}

\section{INTRODUCTION}

The usefulness of induced sputa for the detection of Mycobacterium tuberculosis and Pneumocystis carinii in adults and children has been demonstrated in a number of studies (Shata et al, 1996; Zar et al, 2000; Valerie et al, 1989; Ognibene et al, 1989). Sputum induction was found to be better than gastric lavage for isolation of mycobacterium tuberculosis in infants and young children. Although continuous monitoring of arterial oxygen saturation during sputum induction could not be done, sputum induction was reported to be well tolerated, even in children who were hypoxic or who had Acquired Immune Deficiency Syndrome (AIDS) (Zar et al, 2000). The method entails the collection of sputum after nebulisation with salbutamol, nebulisation with hypertonic saline and chest physiotherapy consecutively. Side-effects reported in the literature include occasional nausea, vomiting (Shata et al, 1996; Ognibene et al, 1989), and dyspnoea (Miller et al,

\section{CORRESPONDENCE TO:}

$\mathrm{H}$ van $\mathrm{Wyk}$

PO Box 522,

Parys 9585

Tel: (056) 811-3676 (h), (056) 8II-2700 (w),

Cell: 082 876-7163
1991). Mild epistaxis and wheezing can occur in infants (Miller et al, 1990).

These studies were done on adults and children three years and older, and not on children under the age of 18 months, in which case the therapist usually needs suctioning to obtain sputa samples. No comparison between induced and conventional methods of obtaining sputa could be found in the literature. Oxygen saturation and pulse were not monitored in these studies, and no comparison regarding side-effects had been done.

The aim of this study was to determine the safety of sputum induction compared to the conventional method of obtaining sputum specimen in paediatric patients under the age of 18 months, as induced sputa samples (used to detect specific organisms) are often required by doctors in the hospital setting. No reference could be found in the literature about the frequency of utilisation of sputum induction.

\section{METHODS}

The protocol was approved by the Ethics Committee of the Faculty of Health Sciences, UFS (ETOVS 95/99). Written consent was obtained from the patient's parents or guardian.

A comparative study had been done. Two groups of samples were collected, and the sample served as its own control.
Paired t-tests and $95 \%$ confidence intervals for differences in means were used for statistical analyses.

The samples were obtained from twenty consecutive patients under the age of 18 months, admitted to the paediatric ward of Universitas Hospital, Bloemfontein, South Africa, with clinical signs of lower airway infection, during the period May to December 1999. Each patient was examined and diagnosed by the same paediatrician. Exclusion criteria for the study were patients with severe pneumonia admitted to the Intensive Care Units and patients with a low oxygen saturation (80\%) or a high pulse rate (above 160 beats/min).

A qualified physiotherapist collected one induced, and one conventional specimen of sputum from each patient as soon as possible after admission. The sputa were obtained on the same day, by means of one method in the morning and the second method in the afternoon. The order of the methods used was alternated daily. As precaution the procedure was performed at least two hours after the last feeding, to reduce oral contamination and the risk of vomiting. Care was taken to prevent a prolonged oxygen saturation level of below $90 \%$. Heart rate was also checked to normalise within a few seconds after rising above the normal range. If normalisation would not occur rapidly, 
the procedure was to be stopped and the patient stabilised. The patient would, however, remain in the statistical analysis at the end of the study. The normal value of oxygen saturation is above $90 \%$. An oxygen saturation of $80 \%$ to $90 \%$ constitudes mild hypoxia with no danger for the patient. Normal heart rate ranges from 100 to $160 \mathrm{bpm}$ for this age group. Pulse and saturation readings were taken using a pulseoximeter (Ohmeda Biox 3740) prior to the procedure, after the salbutamol inhalation, after the saline inhalation, directly after the suctioning, as well as 30 seconds after suctioning. The lowest oxygen saturation and highest pulse rate during each component of the procedures (including chest physiotherapy) were recorded.

For induced sputum production the patient was nebulised with $5 \mathrm{mg}$ Salbutamol via jet nebuliser and face mask (or head-box) for 10 minutes, followed by $5 \mathrm{ml}$ of hypertonic saline $(5 \%)$ over 10 minutes. The acorn nebuliser was connected to a flow meter (flow rate $4 \mathrm{~L} / \mathrm{min}$ ) at the oxygen point in the room. Following nebulisation, chest physiotherapy which included percussion and postural drainage (localised for each child's specific condition), vibration, shaking as well as repeated stimulation of the cough reflex as necessary was applied. No percussion (only postural drainage) would have been used on a patient suspected of having TB, but none of the patients included in the study presented with TB. The duration of chest physiotherapy was about 10 minutes for each patient. Oropharyngeal or nasopharyngeal suctioning was performed with a sterile mucus extractor immediately after productive coughing. The duration of the whole procedure was about 35 minutes.

The conventional sputum was obtained by suctioning after the application of chest physiotherapy only. Physiotherapy and suctioning were performed in the same way as for the induced method. The duration of the whole procedure was 15 minutes for the conventional method.

The patient was observed for possible adverse effects (epistaxis, vomiting, coughing) during the procedure and for 30 minutes following the procedure.

Table 1: Oxygen saturation

\begin{tabular}{|l|c|c|c|c|c|}
\hline \multicolumn{5}{|l|}{ INDUCED N=20 } \\
\hline Variable & Mean & Std Dev & Minimum & Maximum & Median \\
\hline $\begin{array}{l}\text { Prior to } \\
\text { procedure }\end{array}$ & 93 & 5.1 & 83 & 100 & 93.0 \\
\hline $\begin{array}{l}\text { After } \\
\text { Salbutamol } \\
\text { inhalation }\end{array}$ & 96.2 & 5.2 & 82 & 100 & 98.0 \\
\hline $\begin{array}{l}\text { After } \\
\text { Saline } \\
\text { inhalation }\end{array}$ & 96.1 & 4.4 & 84 & 100 & 97.5 \\
\hline $\begin{array}{l}\text { Minimum } \\
\text { during } \\
\text { procedure }\end{array}$ & 88.5 & 4.7 & 76 & 97 & 88.5 \\
\hline $\begin{array}{l}\text { After } \\
\text { procedure }\end{array}$ & 91 & 3.8 & 83 & 97 & 90.0 \\
\hline CONVENTIONAL N=20 & 87.3 & 6.3 & 72 & 96 & 86.0 \\
\hline $\begin{array}{l}\text { Prior to } \\
\text { procedure }\end{array}$ & 92 & 4.7 & 85 & 100 & 91.0 \\
\hline $\begin{array}{l}\text { Minimum } \\
\text { during } \\
\text { procedure }\end{array}$ & 88.6 & 6 & 72 & 96 & 89.0 \\
\hline $\begin{array}{l}\text { After } \\
\text { procedure }\end{array}$ & 87.3 & & & \\
\hline
\end{tabular}

The same physiotherapist obtained all the specimens. Alterations in chest physiotherapy techniques (postural drainage positions and percussion localised for each child's specific condition) were applied in the same way for induced and conventional sputa on a specific patient. The same saturation monitor was used throughout the project.

\section{RESULTS}

Twenty patients were included in the study, 9 boys, and 11 girls. The ages ranged from three weeks to 16 months of age with a median age of seven months. No patient dropped out of the study because of prolonged decreased oxygen saturation of increased heart rate during the procedures.

Measurements of oxygen saturation and heart rate before, during, and after the procedures are summarised in Tables I and 2.

There was no difference in the mean values of the lowest saturation level during the procedure irrespective of the method (p-value 0.184 ) or in the mean values of the saturation before the procedure (p-value 0.218). After the procedure the saturation level with the induced method was higher than with the conventional method ( $\mathrm{p}$-value 0.028 ). The $95 \%$ confidence interval for this difference is 0.3 to 3.9 which is not considered clinically meaningful.

During the collection of three of the 40 specimens, the oxygen saturation dropped to below $80 \%(76 \%, 72 \%$ and $73 \%$ ). The oxygen saturation level dropped to $76 \%$ with percussion in one of the subjects whilst using the conventional method and in the same subject to $72 \%$ (also with percussion) during the induction method. In this child, who was three months old, the oxygen saturation level returned to above $80 \%$ within a few seconds in both methods. However, the saturation level returned to baseline (oxygen saturation level prior to procedure) within one minute after the procedure whilst using the induced method and one minute to baseline with the conventional method. In the second child, who was seven months old, the oxygen saturation level dropped to $73 \%$ with percussion during the conventional method. This low level of saturation lasted only a few seconds before returning to above $80 \%$, and normalisation to baseline took 4 minutes. This child was 
Table 2: Heart rate

\begin{tabular}{|l|l|l|l|l|l|}
\hline \multicolumn{5}{|l|}{ INDUCED N=20 } \\
\hline Variable & Mean & Std Dev & Minimum & Maximum & Median \\
\hline $\begin{array}{l}\text { Prior to } \\
\text { procedure }\end{array}$ & 147.6 & 14.6 & 110 & 170 & 147.5 \\
\hline $\begin{array}{l}\text { After } \\
\text { Salbutamol } \\
\text { inhalation }\end{array}$ & 147.8 & 17.2 & 120 & 178 & 146.5 \\
\hline $\begin{array}{l}\text { After } \\
\text { Saline } \\
\text { inhalation }\end{array}$ & 150 & 16.9 & 116 & 180 & 148.0 \\
\hline $\begin{array}{l}\text { Minimum } \\
\text { during } \\
\text { procedure }\end{array}$ & 164.5 & 14.1 & 140 & 185 & 170.0 \\
\hline $\begin{array}{l}\text { After } \\
\text { procedure }\end{array}$ & 153.1 & 19 & 125 & 180 & 160.0 \\
\hline CONVENTIONAL N=20 & 153.5 & 17 & 112 & 178 & 147.5 \\
\hline $\begin{array}{l}\text { Prior to } \\
\text { procedure }\end{array}$ & 143.3 & 19.9 & 101 & 182 & 157.0 \\
\hline $\begin{array}{l}\text { Minimum } \\
\text { during } \\
\text { procedure }\end{array}$ & 156.1 & 16.5 & 130 & 189 & 160.0 \\
\hline $\begin{array}{l}\text { After } \\
\text { procedure }\end{array}$ & 152.3 & & & & \\
\hline
\end{tabular}

Table 3: Stage of lowest oxygen saturation

\begin{tabular}{|l|l|l|}
\hline Lowest Saturation & Induced $\mathbf{n = 2 0}$ & Conventional $\mathbf{n}=\mathbf{2 0}$ \\
\hline Percussion & 6 & 13 \\
\hline Suction & 10 & 5 \\
\hline Other & 4 & 2 \\
\hline
\end{tabular}

crying, which could have an effect on the oxygen saturation level. These three children had saturation levels of less than $90 \%$ before the procedure. In total, nine children (13 specimens) had oxygen saturation levels below $90 \%$ prior to the procedure. During both the procedures, oxygen saturation remained above $80 \%$ in 10 of these 13 specimens.

The stage of the procedure during which the lowest saturation level occurred was also recorded (see Table 3 ). During the induction procedure, the lowest saturation level occurred during suction in 10 of the 20 patients in the sample, during percussion in six, and at other stages in four subjects. Using the conventional procedure, the lowest saturation level occurred during percussion in 13 of the 20 patients in the sample, during suction in five of 20 , and at other stages in two.
There was no difference in the mean values of the heart rate before ( $\mathrm{p}$-value $=0.126$ ) or after the procedure ( $\mathrm{p}$-value $=0.865)$ irrespective of the method. The mean peak heart rate during the procedure was slightly higher ( $\mathrm{p}$-value $=0.040)$ during the induced sputum procedure (165 beats/min) as compared to the conventional procedure ( 156 beats $/ \mathrm{min}$ ). The $95 \%$ confidence interval for this difference is 0.6 to 13.4 . The highest recorded heart rate was $189 / \mathrm{min}$, and occurred during the conventional procedure. No prolonged tachycardia occurred in any of these cases. None of the children developed a bradycardia during the procedure.

Saline inhalation caused increased coughing in twelve patients, but only mild coughing with less than five coughs per episode. The oxygen saturation was not influenced dramatically by this coughing. Increased coughing was also caused by chest physiotherapy in both the induced and conventional methods, but no severe coughing was noted.

Mild epistaxis occurred in seven of the 20 cases during the induced sputum method and in four of the 20 cases during the conventional method, after suctioning. The sputa did not contain any blood. Mild vomiting occurred in one patient just after suctioning during the induction method.

\section{DISCUSSION}

No clinically meaningful differences in oxygen saturation measurements were found between the induced and the conventional methods of obtaining sputum.

Of note however, was that the lowest saturation measurement occurred more frequently with percussion during the conventional method than with the induced method. It thus seems that percussion is tolerated better during the induced sputum method. A possible explanation could be that bronchodilatation after nebulisation with salbutamol increases the tolerance for percussion.

The mean peak heart rate was slightly higher during the sputum induction method ( 165 beats/min) than during the conventional method (156 beats/min). This is probably due to the nebulisation with salbutamol. Though statistically significant, this difference is too small to be of clinical importance.

Adverse effects such as increased coughing, mild epistaxis due to suctioning and vomiting do seem to occur more frequently during the induced sputum technique. These side effects however, are mild. The vomiting in one of the patients was probably triggered by the suctioning and not by the sputum induction. In view of the possibility of vomiting during suctioning, it is important to wait at least two hours after the last feed before collecting sputum.

Bradycardia caused by vagal stimulation could be expected during suctioning of the pharynx, especially in the younger patients. This did not occur in any of the patients. The risk for bradycardia could increase if suctioning was prolonged. Because of this theoretical risk of brady- 
cardia and the fact that the saturation levels dropped below $80 \%$ in three of the 40 sample collections, it seems wise to monitor pulse and oxygen saturation during sputum collection in small children, during both the conventional and the induction method.

\section{CONCLUSION}

Sputum induction is safe in children under 18 months of age. No major differences in oxygen saturation, heart rate or other side effects between the induction method and the conventional method of sputum collection were found.

\section{Clinical implications for physiotherapy}

The method of induced sputum can be used in children under the age of 18 months without compromising the patient's safety.

The induced method of collecting sputum specimen is more cost and time consuming than the conventional method and therefore should be used only when a high yield for virological and bacterial investigations to detect specific organisms is required.

\section{Limitations and suggestions for further studies} This study should be repeated with a larger sample size for more significant statistical analysis.

The differences in yield should be compared using the conventional and induced methods of collecting sputum specimen.

Investigation of the effect of age on methods of sputum collection in children under the age of 18 months would be interesting.

\section{REFERENCES}

Miller RF, Kocjan G, Buckland $J$ et al. 1991 Sputum Induction for the Diagnosis of Pulmonary Disease in HIV Positive Patients. Journal of Infection 23:5-15.

Miller RF, Leigh TR, Collins JV, Mitchell DM. 1990 Tests giving aetiological diagnosis in pulmonary disease in patients infected with the Human Immunodeficiency Virus. Thorax 45:62-65.

Ognibene FP, Gill VJ, Pizzo PA, Kovacs JA, Godwin C, Sufferdini AF, Shelhamer JH, Parrillo JE, Masur H. 1989 Induced sputum to diagnose Pneumocystis carinii pneumonia in immunosuppressed pediatric patients. The Journal of Pediatrics Sept: 430-433.

Shata AMA, Coulter JBS, Parry CM, Ching'ani G, Broadhead RL, Hart CA. 1996 Sputum induction for the diagnosis of tuberculosis. Archives of Diseases in Childhood 74:535-537.

Valerie L, Gartner I, Weymouth LA, Goodman CD. Hopewell PC, Hadley WK. I989 The use of Mucolysed Induced Sputum for the Identification of Pulmonary Pathogens Associated with Immunodeficiency Virus Infection. Archives of Pathology Laboratory Medicine 113:488-493.

Zar HJ, Tannenbaum E, Apolles P, Roux P, Hanslo D, Hussey G. 2000 Sputum induction for the diagnosis of pulmonary tuberculosis in infants and young children in an urban setting in South Africa. Archives of Diseases in Childhood 82:305-308.

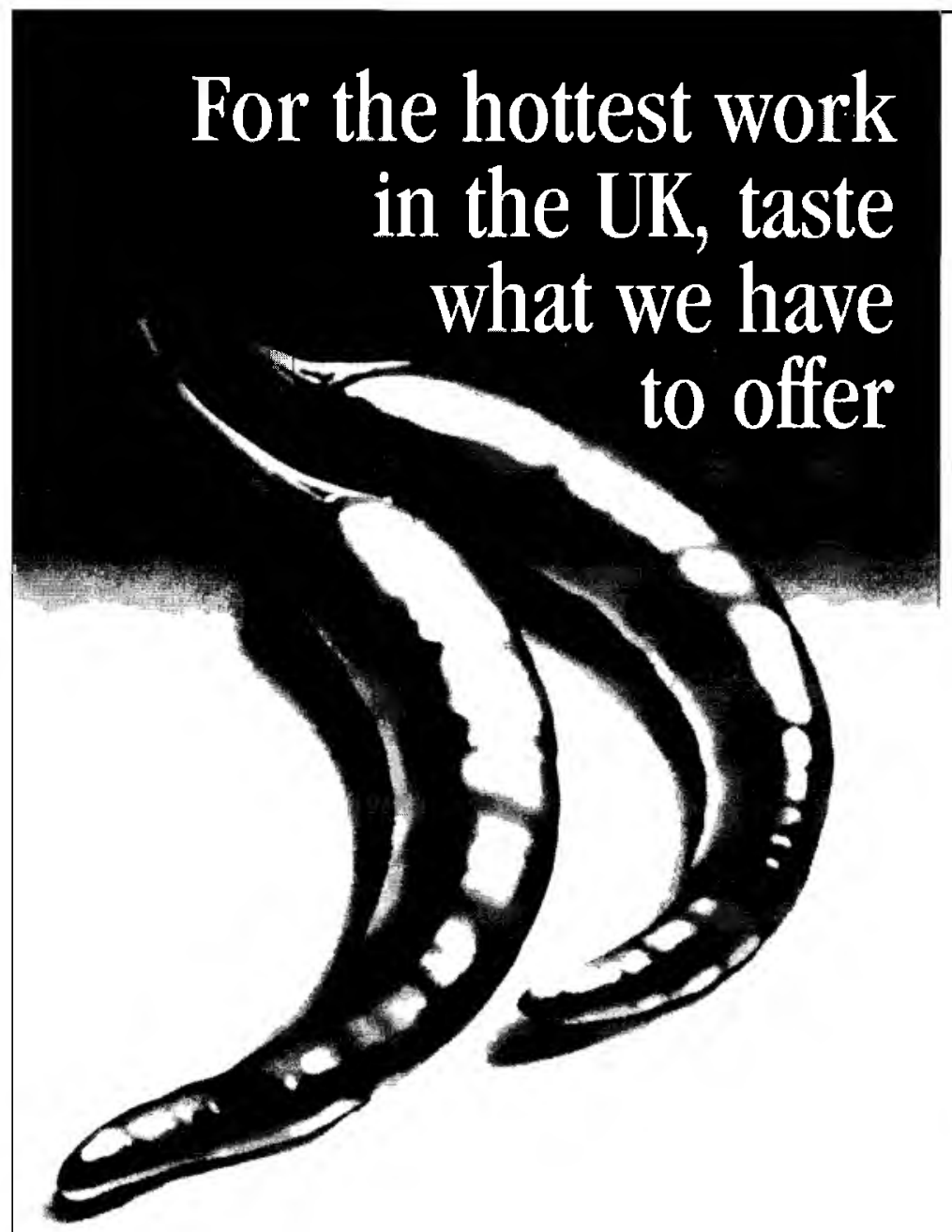

Physiotherapists

- Widest choice of Locum, Permanent and Fixed-Term Contracts

- Advice on:

State Registration

UK Visas and Work Permits

Accommodation

Bank Accounts

- Top rates of pay

- UK CPSM Registration Fees reimbursed

- FREE Holiday Pay

\section{Contact Bridget O'Farrell BScOT} in South Africa on (021) 423-3853

Fax: (021) 423-3855

E-mail: corinth@mweb.co.za

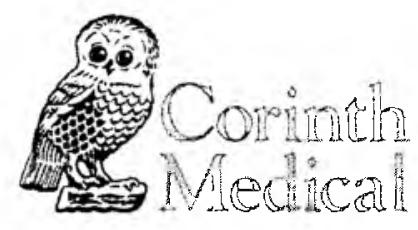

London Office

Toll Free 0800-99-3055 Fax: 09442082076894 E-Mall: pl@corinth.co.uk 